\title{
Adulterated Pharmaceutical Product Detection Using Statistical Process Control
}

\author{
Mostafa Essam Eissa \\ Microbiology and Immunology Department, Cairo University, Cairo, Egypt
}

(Received: August 09, 2017; Accepted: October 30, 2017; Published: January 30, 2018)

\begin{abstract}
Drugs manufactured in pharmaceutical companies - that do not comply to current Good Manufacturing Practice (cGMP) - are considered by Food and Drug Administration (FDA) as "adulterated medicines", even if they did not impose any health or quality risk to the final consumers. Non compliance to cGMP has adverse effects on both customers and companies with think again escalating legal penalties may be issued. In the current study, newly established pharmaceutical plant launched film coated tablet for treatment of common cold symptoms. The local regulatory agency in collaboration with quality team of a well-established pharmaceutical company in the area has conducted large survey that covered new firms to elucidate the compliance of the facilities of those newly emerging companies to cGMP, partially using statistical process control (SPC). The generated results for the product by quality control (QC) and in-process control (IPC) were processed using statistical software packages. Trending of data brought the focus on hardness test which later highlight the need to investigate dissolution pattern of the three active components of the dosage form. Time series plot of hardness for 195 batches manufactured during 2016 showed non consistency and stability of the process which can be segmented chronologically into three distinct segments. A significant negative correlation ( -0.64 by Spearman correlation) was found between the hardness and the dissolution of one the active pharmaceutical ingredient (API) viz, Pseudoephedrine Hydrochloride. Inconsistent operation during hardness as IPC test was reflected in the dissolution QC test. Effect on other properties should be investigated.
\end{abstract}

Key words: cGMP, FDA, Statistical process control, QC, PC, API.

\section{Introduction}

The challenging standards in the pharmaceutical industry have increased significantly during the last few decades so that the reliance on just meeting products specifications becomes obviously not sufficient to judge the quality of the manufacturing process cycle for pharmaceutical firm. Pharmaceutical products that are manufactured in facilities that do not consistently follow current good manufacturing practice (cGMP) are considered by Food and Drug Administration (FDA) "adulterated medicines", even if nothing wrong with delivered product to the final customer (FDA, 2015).

The statistical quality tools offers several advantages if applied for process improvement through better understanding and control for the operation (Chopra et al., 2012). Process-behavior (Shewhart) charts are used to trend results to determine the performance and the state of control of the inspected operation (Shah et al., 2014). The variation within product properties may brought quality problem from the firm to the open market place, if quality tools were used improperly to spot the sources of defects or variations to be corrected (Wachs, 2011).

The present study aimed to investigate the current state of cGMP for new manufacturing facility through monitoring statistical process control (SPC) of launched product through the year 2016 and spotting area of defects through trending of hardness

Correspondence to: Mostafa Essam Eissa; Tel.:+2-0100-6154853; E-mail:mostafaessameissa@ yahoo.com 
for 195 batches manufactured during this year. Further analysis would be applied in case of any abnormalities detected. The work would provide evidence for the true presence of quality control system otherwise corrective measures should be implemented.

\section{Materials and Methods}

Purpose of the study: SPC was applied to assess the degree of compliance and quality of the measured inspection characteristics. If defects or abnormalities were detected, further analysis would be conducted to elucidate the impact on other properties. Importantly, the outcome of the work would determine whether the product is "adulterated" or not although it has passed all in-process control (IPC) and quality control (QC) tests. Moreover, it has been claimed that it has met Ministry of Health $(\mathrm{MoH})$ requirements.

Subject of study: Film coated tablet (FCT) used as over-the-counter (OTC) medication for treatment of common cold symptoms, based on triple active pharmaceutical ingredients viz. Paracetamol, Chlorpheniramine Maleate and Pseudoephedirine Hydrochloride. The primary inspection properties would be the friability during machine setup of compression machine and hardness, average weight and disintegration which are determined during the compression phase of tablet core before coating stage. These tests are part of IPC and the remaining test that could be inspected would be the dissolution of the three components test which should be performed in QC laboratory after primary packaging of the product.

Company specifications of the inspection characteristics: Dissolution rate should not be less than (NLT) $70 \%$ after 45 minutes and hardness was claimed to be 15-20 Kiloponds (Kp) but has been amended to be 9-20 Kp. For tablet weight, the criterion was set to $800 \mathrm{mg} \pm 5 \%$ and disintegration time should not exceed 15 minutes. Maximum allowable limit for friability is $1 \%$ with no defects is apparent in the tablets shape.

Site of preliminary investigation: Class D production plant of solid dosage form in newly established pharmaceutical plant based on the industrial zone, Egypt. Data mining were mainly from compression room in production area, quality assurance (QA) and QC departments (Eissa et al., 2016).

Results processing: Raw data collections were pooled into QA department and arranged in excel sheets for further processing. Based on the recorded results number configuration, data could be classified as discrete or variable type which consequently determine the selection of the type of control charts (Szoka, 1982; Breyfogle et al., 2001). Results were analyzed statistically using Graph Pad Prism 6 for Windows (Motulsky 2003). SPC tools were implemented using Minitab ${ }^{\circledR}$ 17.1.0 (Wakefield et al., 2011; Triola, 2014).

\section{Results and Discussion}

SPC tools have been applied previously and demonstrated clearly unseen defects in the manufacturing process that required corrections, although the studied product has met the specifications in other pharmaceutical plants (Eissa and Abdoh, 2016). Column statistics showed that most data did not follow normal distribution with presence of several freak results that distort the distribution. Accordingly, Spearman correlation was sought to be appropriate choice to find correlation between inspection properties (Mukaka, 2012). The correlation matrix in table 1 clearly demonstrated insignificant to low correlation (the remaining were omitted because of very low values). An exception moderate negative correlation existed between both hardness and dissolution of Pseudoephedrine Hydrochloride (Witz et al., 1990). This brought the focus into hardness first for analysis using SPC. Figure 1 showed abnormal pattern of data when batches arranged chronologically.

Box-and-Whisker showed apparently no outliers lots of product, showing the strong shift of the median in relation to lower and upper quartiles in addition to minimum and maximum observations (SAS/STAT 9.2 user's guide, 2009). Time series graph in figure 1 explained the distortion by showing three non-normal segmented variabilities: Initial high 


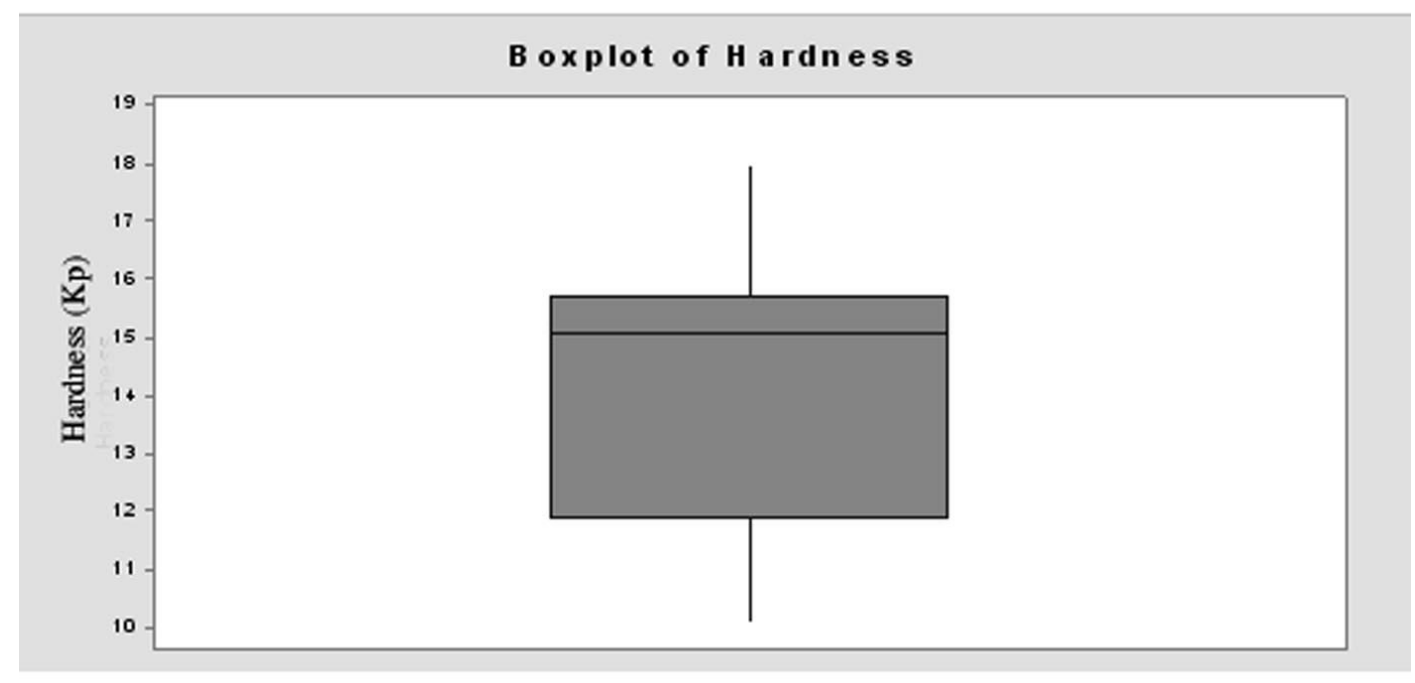

Time Series Plot of Hardness
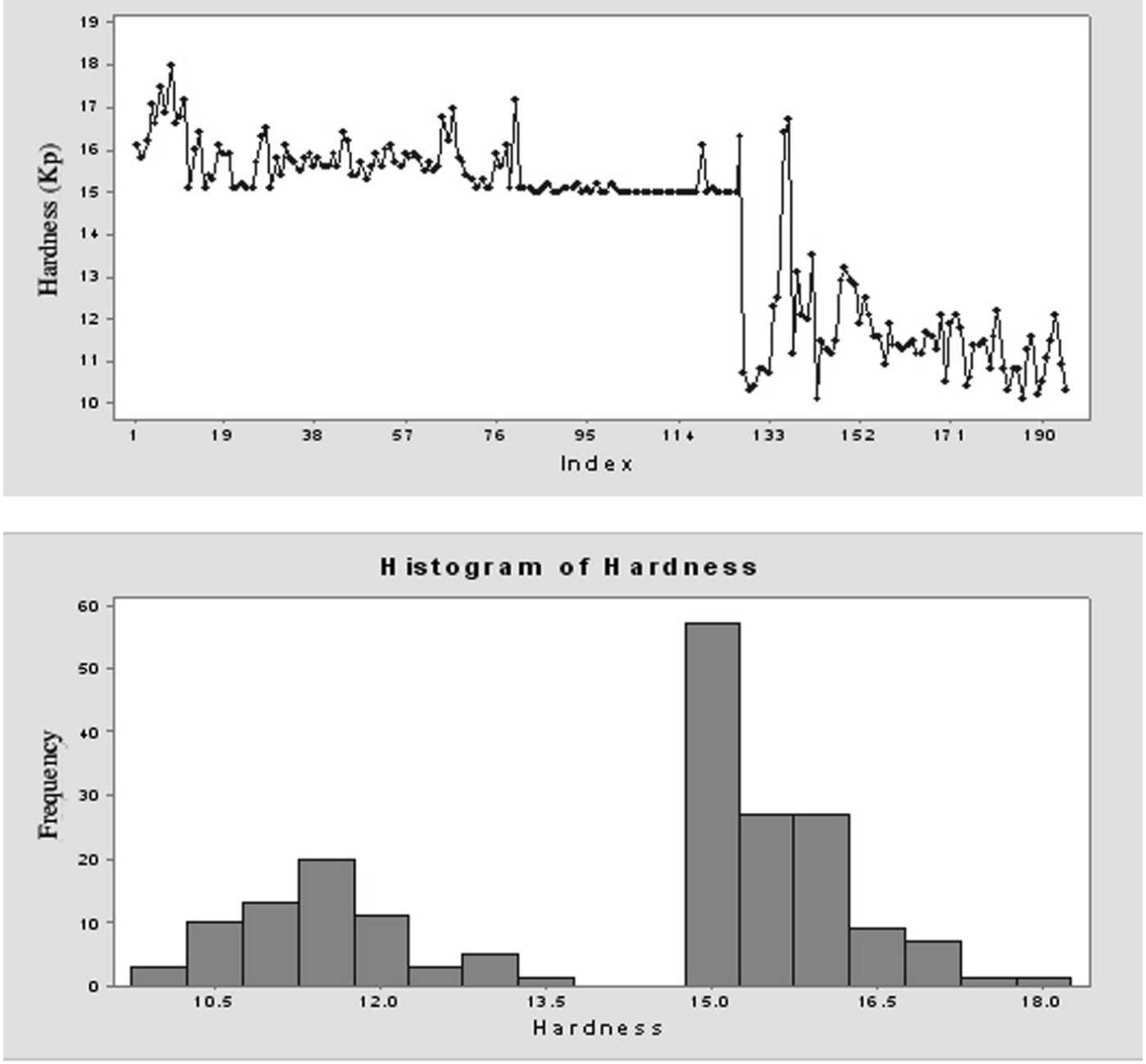

Figure 1. Box plot diagram, run chart and histogram analysis performed on hardness test. 
Table 1. Correlation matrix between hardness and dissolution results.

\begin{tabular}{lcccc}
\hline Spearmancorrelation* & Hardness & $\begin{array}{c}\text { Dissolution of } \\
\text { Paracetamol }\end{array}$ & $\begin{array}{c}\text { Dissolution of } \\
\text { Chlorpheniramine } \\
\text { Maleate }\end{array}$ & $\begin{array}{c}\text { Dissolution of } \\
\text { Pseudoephedrine } \\
\mathrm{HCl}\end{array}$ \\
\hline Hardness & 0.19 & 0.25 & $-0.64 \Psi$ \\
\hline Dissolution of Paracetamol & 0.00 & 0.00 & $0.36 \dagger$ & 0.13 \\
\hline $\begin{array}{l}\text { Dissolution of } \\
\text { Chlorpheniramine Maleate }\end{array}$ & 0.00 & 0.06 & 0.06 & -0.13 \\
\hline $\begin{array}{l}\text { Dissolution of } \\
\text { Pseudoephedrine } \mathrm{HCl}\end{array}$ & & & & \\
\hline
\end{tabular}

*All showed negligible correlation except $\uparrow$ (weak positive correlation) and $\Psi$ (moderate negative correlation) (Mukaka, 2012).

(hardness I), middle steady (hardness II) and end low (hardness III) have been shown. Each segment showed intermittent clustering of special cause variation due to extraneous factors and process mean shift, indicating totally unstable process as illustrated in Figure 2. Red dots indicates batches with assignable causes of variations that require further investigation (Eissa et al. 2015). On the other hand, histogram in Figure 1 clearly illustrates performance of different operations into one process with the right one being truncated by screening or review action with results were forced to not exceed the lower limit of $15 \mathrm{Kp}$ (Tague 2004). It is actually overlap of hardness I and II. Box-and-Whisker and histogram in Figure 1 were dissociated in Figure 3, showing each section separated with outliers being prominent and the characteristic pattern at each period was resolved. Figure 4 and 5 showed the remaining inspection characteristics with out-of-control points being not in them all indicating the presence of assignable causes of variations interrupting normal operations. Interestingly, it should be noted that the dissolution Pseudoephedrine Hydrochloride showed reversely similar profile to hardness test but can be separated into two sections only (I and II) in Figure 4.

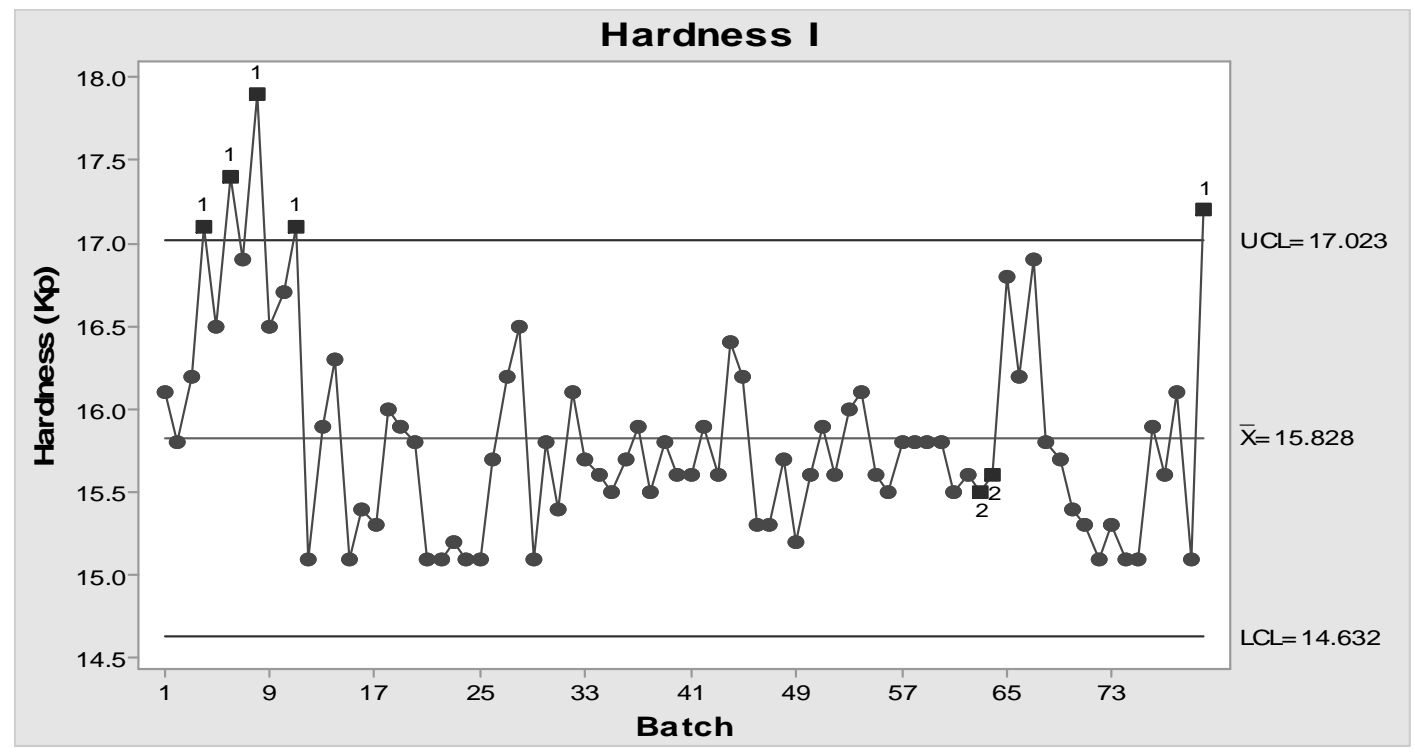




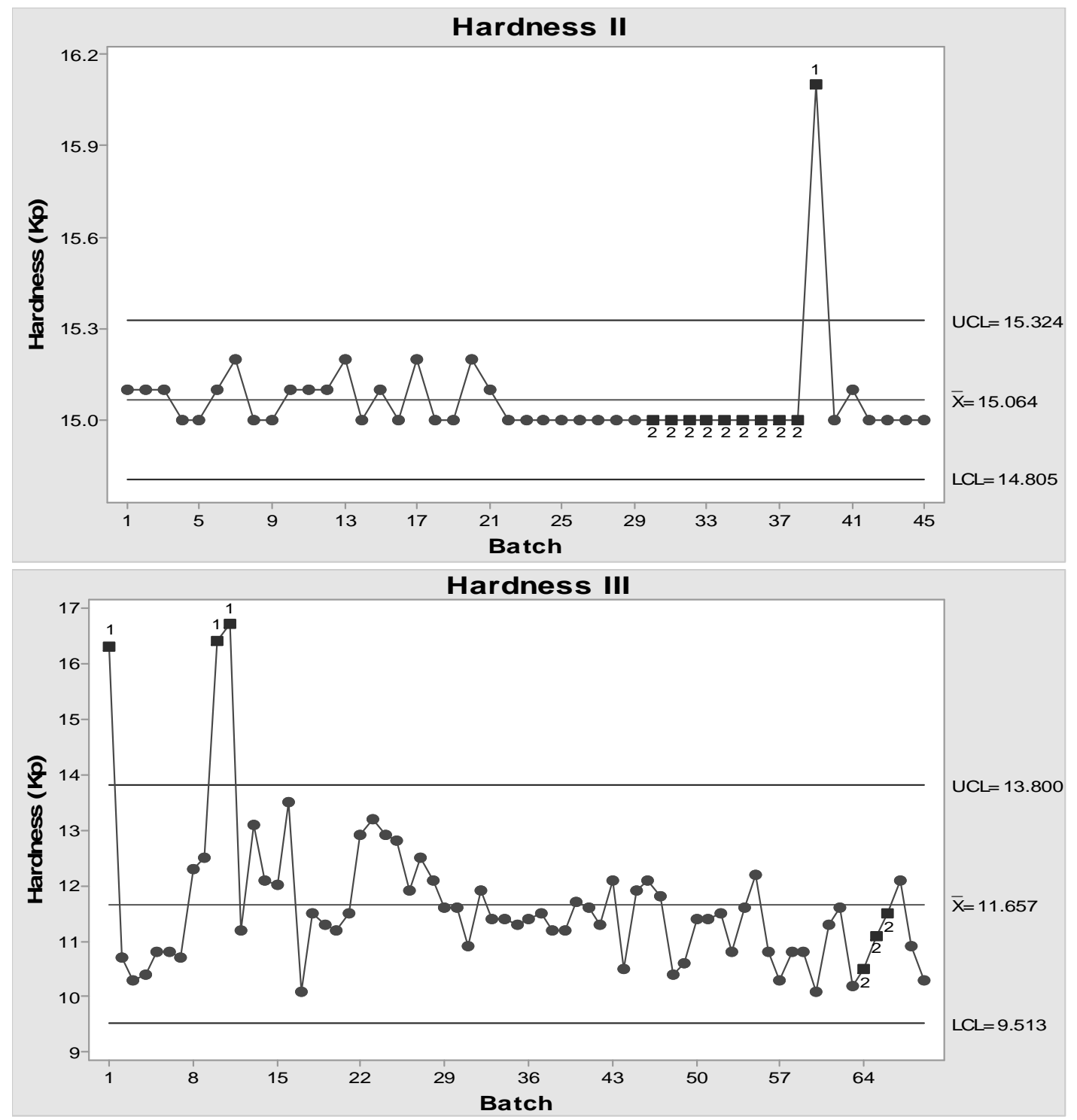

Figure 2. Control charts on three chronologically successive stages of hardness test

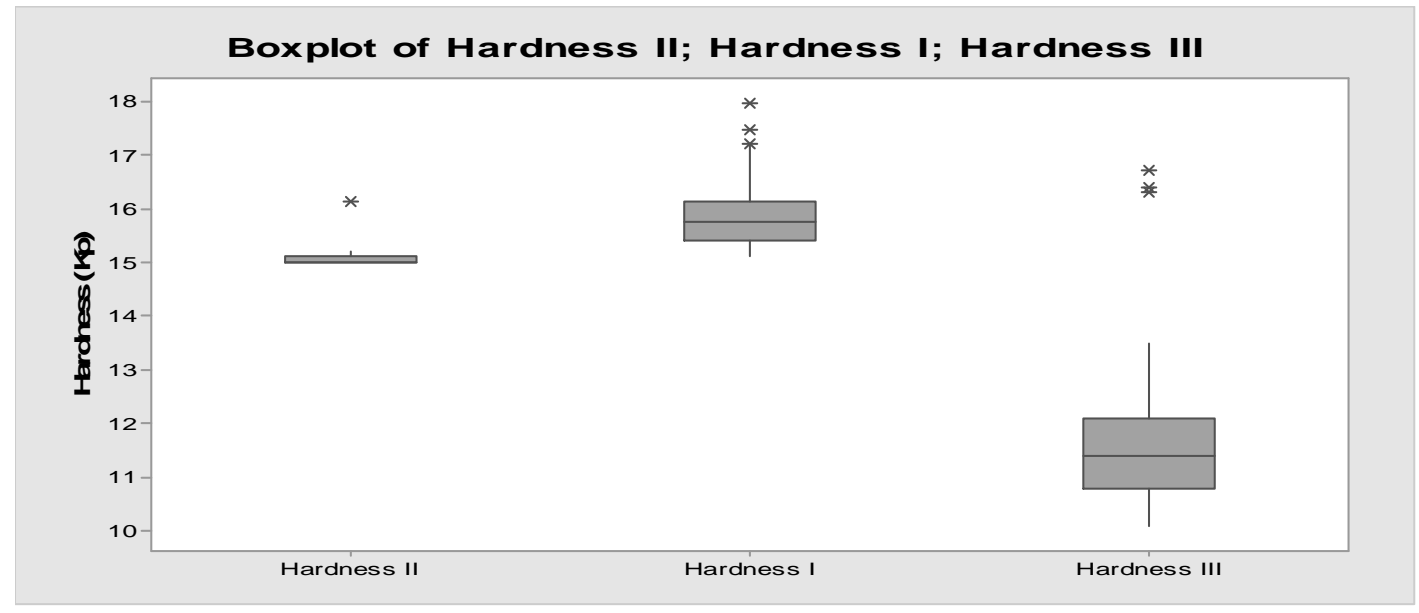




\section{Histogram of Hardness I}

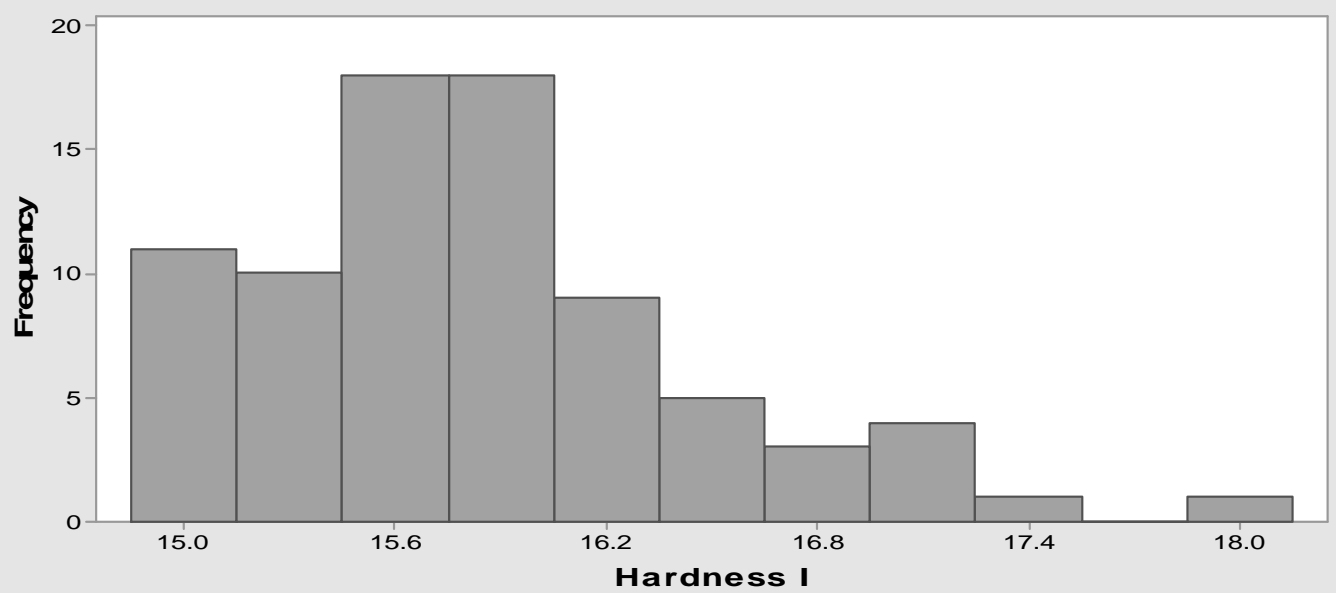

Histogram of Hardness II

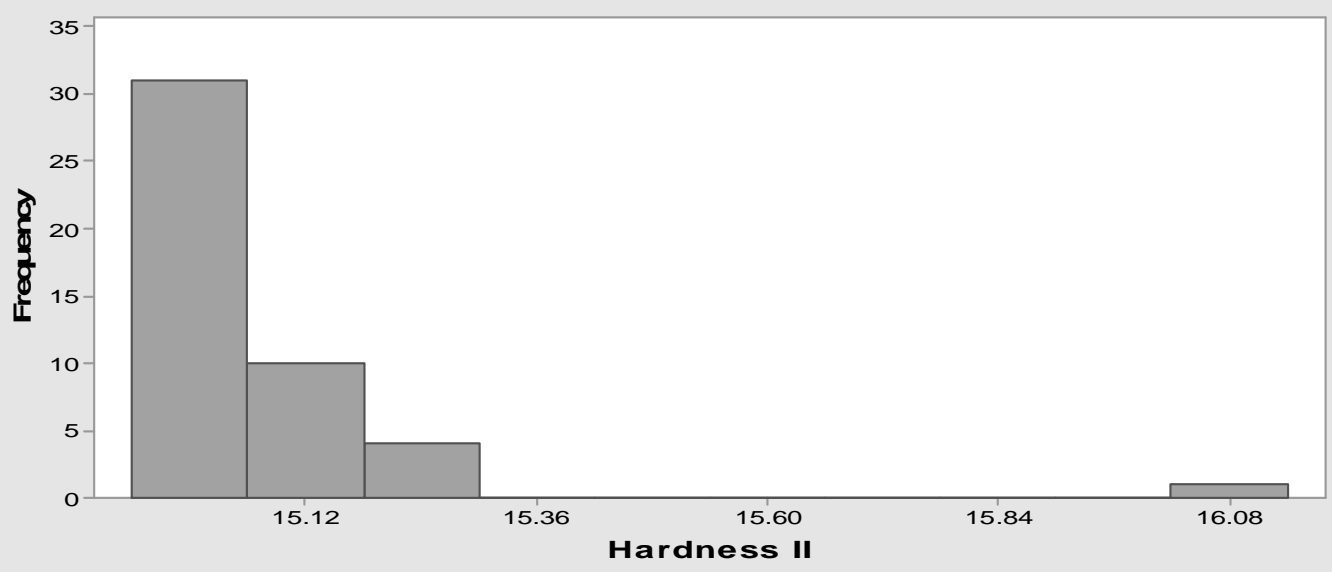

Histogram of Hardness III

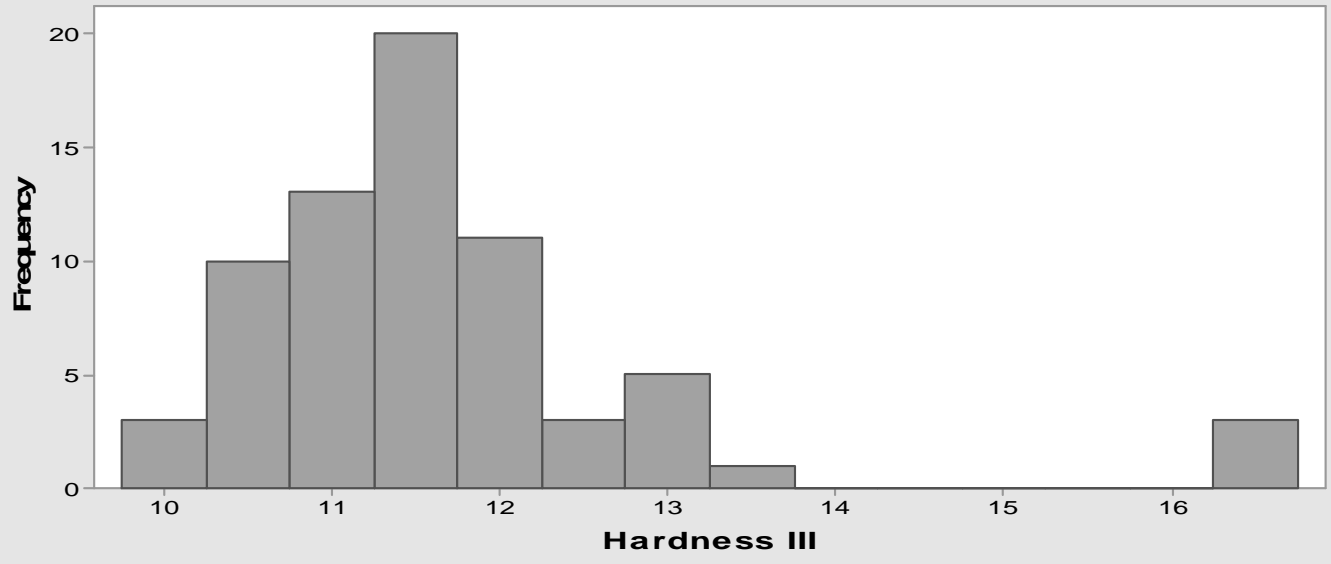

Figure 3. Sectioned hardness profile chronologically (I, II and III) showing outliers. 

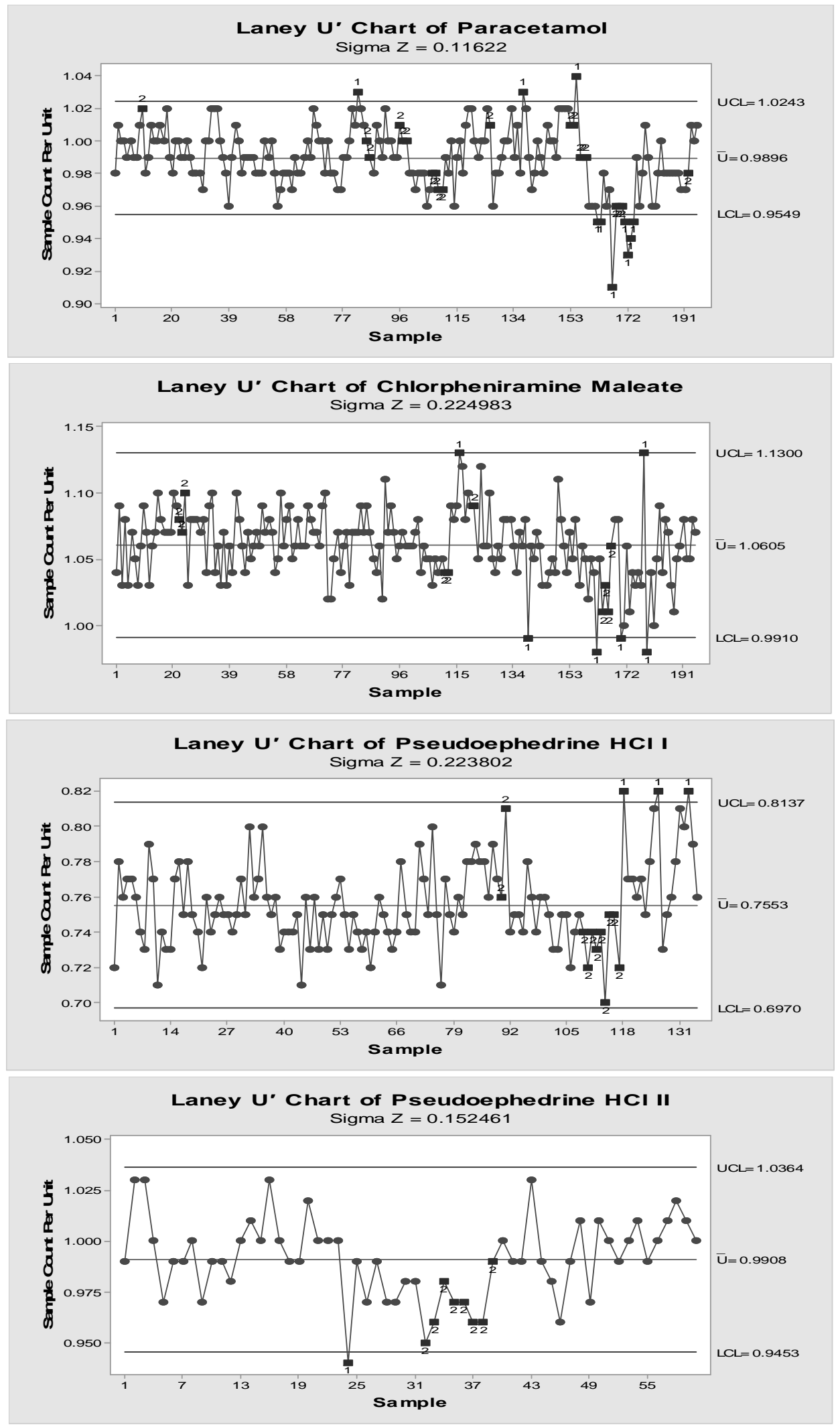

Figure 4. Dissolution charts of APIs with specifically two sections for Pseudoephedrine Hydrochloride. 


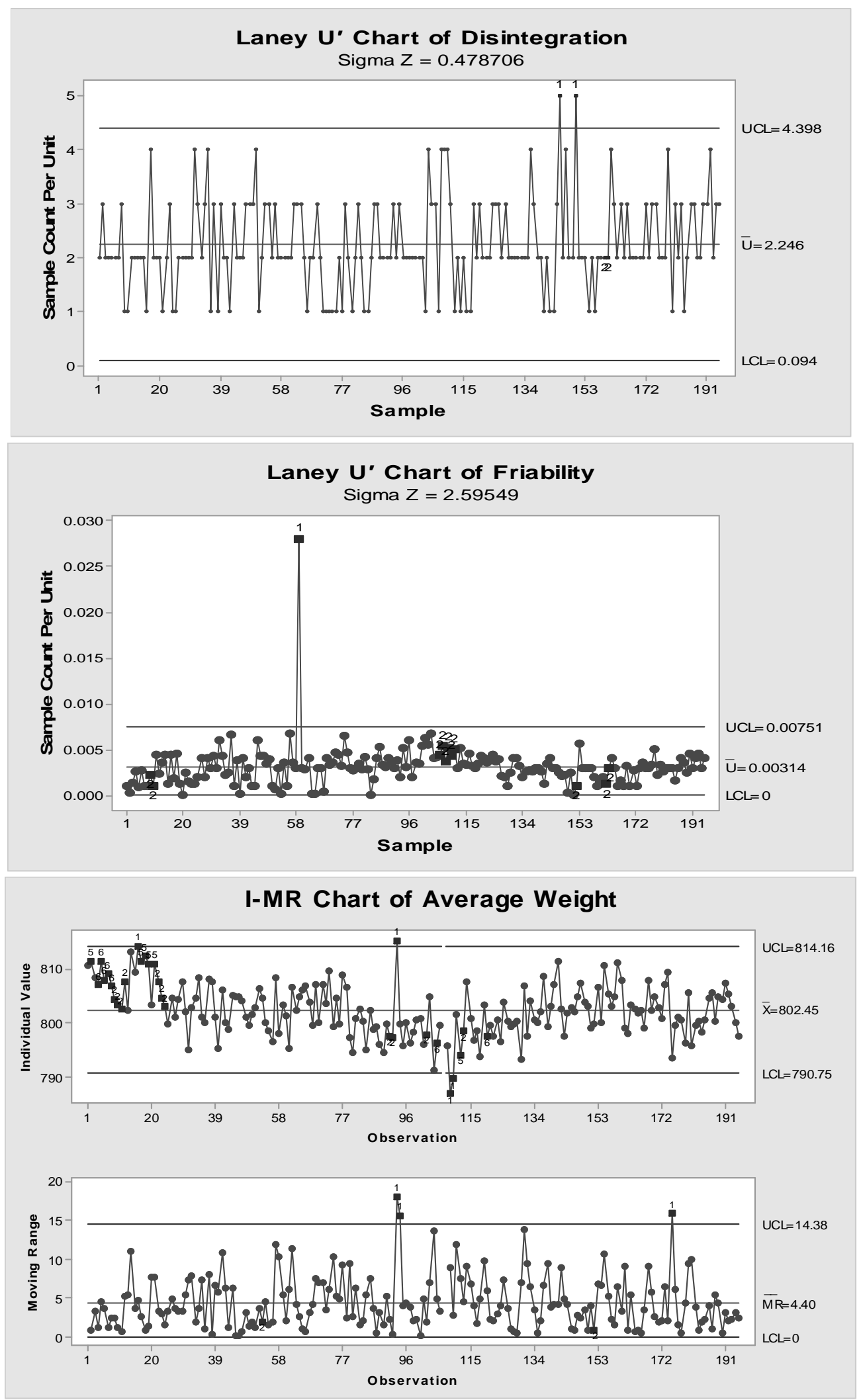

Figure 5. Control charts for IPC tests: disintegration, friability and average weight. 


\section{Conclusion}

Although full potential of SPC could be revealed when applied from the beginning of any projects to adjust process stability and achieve improvements in the future, yet retrospective analysis would provide supportive analysis for the past situation for corrective actions and preventive actions (CAPA) in the future. The investigated firm did not apply SPC efficiently and the full reliance for product acceptance was centered on release specifications. However, the consequences were devastated and required product recall and stoppage of the production line till full correction of the causes. The non compliance to cGMP has led to adulterated medicinal dosage form. Moreover, the product Safety, Identity, Strength, Purity and Quality (SISPQ) appeared to be affected. But the continuation of manufacturing by the firm seems to be indication of poorly understood operation coupled with underestimation of GXP rules.

\section{References}

Breyfogle, F., Cupello, J. and Meadows, B. 2001. Managing Six sigma. 1st ed. New York: Wiley, USA.

Chopra, V., Bairagi, M., Trivedi, P. and Nagar, M. 2012. A case study: application of statistical process control tool for determining process capability and sigma level. PDA J. Pharm. Sci. and Tech. 66, 98-115.

Eissa, M. and Abdoh, A. 2016. Evaluation of quality characteristics and process stability for pharmaceutical dosage form using attribute control charts. IJAMS. 1, 9-15.

Eissa, M., Mahmoud, A. and Nouby, A. 2016. Evaluation and failure risk of microbiological air quality in production area of pharmaceutical plant. RGUHS J. Pharm. Sci. 5, 155-166.

Eissa, M., Seif, M. and Fares, M. 2015. Assessment of purified water quality in pharmaceutical facility using six sigma tools. Int. J. Qual. Assur. 6, 54-72.
Food and Drug Administration (FDA). 2008. Guidance for industry: CGMP for phase 1 investigational drugs. Food and Drug Administration, Rockville, MD.(Online.) http://www. fda. gov/downloads/Drugs/GuidanceComplianceRegulator yInformation/Guidances/UCM070273. pdf.

Motulsky, H. 2003. GraphPad Prism. 1st ed. San Diego, Calif.: Graph Pad Software, USA.

Mukaka, M.M. 2012. A guide to appropriate use of correlation coefficient in medical research. Malawi Med. J. 24, 69-71.

SAS/STAT 9.2 user's guide. 2009. 1st ed., Cary, N.C.: SAS Institute.

Shah, S., Shridhar, P. and Gohil, D. 2014. Control chart: A statistical process control tool in pharmacy. Asian Journal of Pharmaceutics (AJP): Free full text articles from Asian J. Pharm. 4, 184-192.

Szoka, K. 1982. A guide to choosing the right chart type. IEEE Transactions on Professional Communication. PC 25, 98-101.

Tague, N. 2004. The Quality Toolbox. 2nd ed. Milwaukee: ASQ Quality Press, USA.

Triola, M. 2014. Minitab manual. 1st ed. Boston, Mass.: Pearson Education, USA.

US Food and Drug Administration (FDA). 2015. Facts about the current good manufacturing practices (CGMPs).

Wachs, A. 2011. PhD Research. Misapplications of SPC and the Consequences, 'Many manufacturing leaders believe that their production personnel use SPC properly, but the evidence suggest otherwise.

Wakefield, D., McLaughlin, K. and Stine, R. 2011. Minitab manual. 1st ed. Boston, MA: Pearson Addison Wesley, USA.

Witz, K., Hinkle, D., Wiersma, W. and Jurs, S. 1990. Applied Statistics for the Behavioral Sciences. J. Edu. Stat. 15(1), 84.

Zhou, M. 2011. Competitiveness of bioanalytical laboratories-technical and regulatory perspectives. The Quality Assurance J.. 14, 65-71. 